\title{
The Emergence of the Yangtze River Delta and the Responses of Busan and Kaohsiung
}

\author{
Chen Tao*
}

\begin{abstract}
The Yangtze River Delta (YRD) has become the world's most important containerexport area in the world because of the huge growth of container volume from China. Shanghai, the gateway of the YRD, handles most of the cargoes. But the nature of river port has restricted its development, which forced China to built the Yangshan deepwater port to act as the mega hub in the region. In response to the emergence of the YRD and Yangshan, two traditionally transshipment centers in the region, Busan and Kaohsiung, have implemented strategies to in response to the emergence of YRD and Yangshan. This paper analyzes Busan's and Kaohsiung's strategies and tries to forecast the development of these ports. Research result shows Busan is aggressive and ambitious but that Kaohsiung has little chance of becoming the mega-hub in the region.
\end{abstract}

Keywords : Hub-spoke network, container terminal, Busan, Kaohsiung.

\section{Hub and Spoke Network}

The container-shipping industry adopted the hub-spoke concept years ago. The strong growth of container volume in southern and central China has encouraged shipping lines to place orders for bigger containerships, and the growth of the storage capacity of containership further forcing shipping lines to select a hub port for efficient transport of containers in the region. Major ports in Asia thus have no choice but to compete with each other to be the mega-hub.

After decades of years of hub-port development, two models of hub and spoke networks have developed in Asia (see figure 1). In the Singapore model, only one megahub acts as the gateway of international transport in the region(in respects to the container volume handled). In the Hong Kong model, several ports act as the gateways of cargo flow through the Pearl River Delta (PRD).

In northeast Asia, two traditional hubs - Busan, South Korea and Kaohsiung, Taiwan - are facing a challenge from the Port of Shanghai. The major focus of this study is

Submission Date : 9/20/2005 Acceptance Date : 11/30/2005

"Corresponding Author : Assistant Professor, Department of Shipping and Logistics Management, Kainan University, Taoyuan, Taiwan, E-Mail: chentao@mail.knu.edu.tw 
whether the development of hub-spoke networks is likely to follow the Singapore model or the Hong Kong one.

Figure 1. Two models of hub-spoke networks

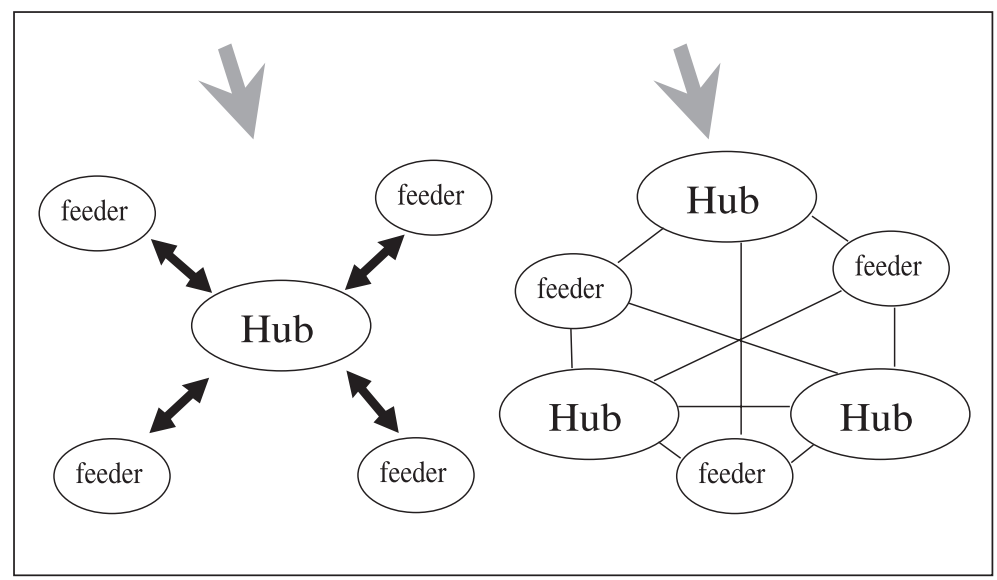

To maintain competitiveness and attract mega containerships, ports have adopted strategies to improve the business environment and have invested billions of dollars in the construction of modern container terminals. Shanghai, Busan and Kaohsiung have announced projects to keep ahead of the competition, and most of these ports have completed the first phases of their port-expansion projects (for example, Yangshan Port and Busan New Port). Therefore, now is an appropriate time to examine the possible development in the region. Two perspectives are taken to examine their development and impacts. The first is the supply and demand of container-handling capacity (whether there is excess capacity reserved for transshipment business); the second is the quality of the business environment, as assessed by the results of a questionnaire designed to be answered by both senior managers of shipping lines and port authorities to quantify the differences between these ports. The development of a hub-spoke network, therefore, could be examined from the viewpoints of both "hardware" and "software."

\section{The Emergence of YRD}

Most research (for example, that of De Monie(1998)) on the transshipment business has pointed out there is only one global mega port in the region and that most of the containers have to be transshipped via the "mega" port, which alone enjoys the advantage of the most efficient and cost-effective shipping service. The Asian experience shows the "mega-hub" could be either only one mega port or a group of ports. From the viewpoint of YRD, it's clear that several ports will act as "global hubs." But which ports will join the "port group"? 
Figure 2. Global hub network

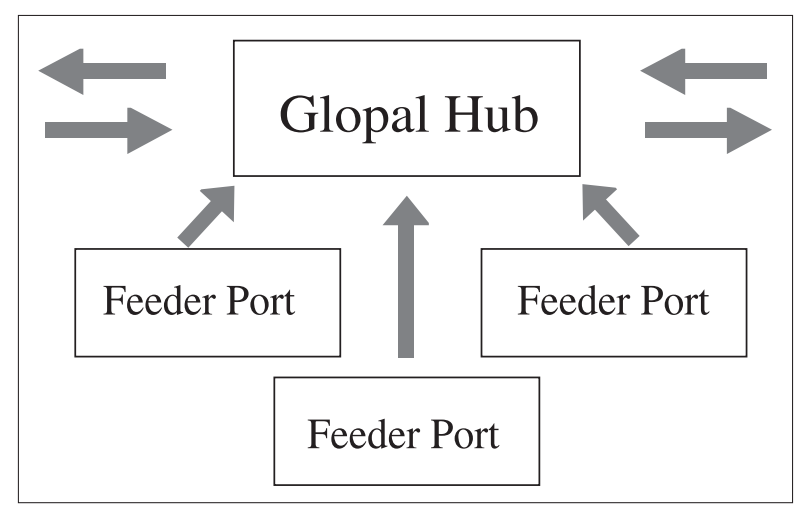

In the 1990s, China became the largest container-exporting country. China, however, is still short of modern container handling capacity, which has forced domestic containers to be transshipped via ports in areas neighboring China. The emergence of container shipping business in the Yangtze River Delta (YRD) is the second chance for neighboring port to share the transshipment business, the gap between the supply and demand of container handling capacity seems will not be solved in the near future, which provide the chance for neighboring ports (for example, Busan and Kaohsiung) to play the role of "global hub."

\section{Supply and Demand of Handling Capacity in the Region}

To know the demand for container handling capacity, the first task is to estimate the future container volume of these ports. There are several ways of doing this, the most common being to estimate the GDP and the ratio of general cargo to be containerized. Another method is to assume several possible scenarios and estimate the possible development of container volume under these scenarios. This study adopts the second method.

The scenarios are made based on two conditions: the outlook of economic stability and the outlook of political stability of the country. The relationships between container volume growth rate and scenarios are illustrated below:

Table 1. Container volume growth rate under different scenarios

\begin{tabular}{c|c|c}
\hline Economic/Political outlook & Pessimistic & Optimistic \\
\hline Pessimistic & Low & Medium \\
\hline Optimistic & Medium & High \\
\hline
\end{tabular}

The container volumes of the Port of Shanghai, Busan and Kaohsiung between 1994 and 2004 were collected as the base for analysis. Less than $1 \%$ of the transshipment business was in Shanghai, while Busan and Kaohsiung enjoyed more than $40 \%$ each. Thus, the growth of the container volumes of Busan and Kaohsiung could be subdivided 
into domestic and transship categories.

Based on the historic data, this study estimates throunghput between 2005 to 2015 . But owing to the complexity of variables influencing the future development of container volume, this study projects the possible development only through 2010.

The average growth rate of the ports between 1995 and 2004 is used to estimate the container volume of 2010 under "medium" growth. Growth rates between 1995 and 2004 were further divided into two groups: higher and lower. The average growth rate of the higher ones is used for the estimation of "optimistic" condition and the lower one for "pessimistic" condition.

After estimating the demand for container-handling capacity, the second step is to find out the supply. To learn this, first discover the number of container berths available in 2010, which can be estimated by checking relevant Web sites for announcements of development projects. The second step is to estimate the possible handling capacity of these berths based on the performance achieved by the terminal operators of each port. The throughput of terminals in these ports between 2000 and 2004 are collected for analysis. The average throughput achieved by the top 50\% of terminal operators of each port is used to estimate the container handling capacity in 2010.

Figure 3. Container volume of the Port of Shanghai (1995-2004)

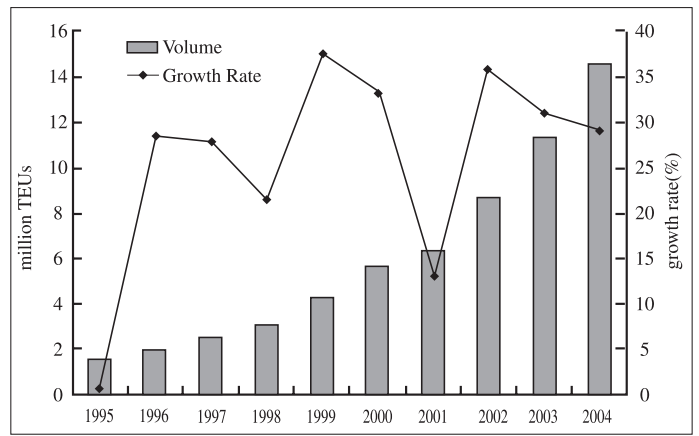

Figure 4. Container volume of the Port of Busan (1995-2004)

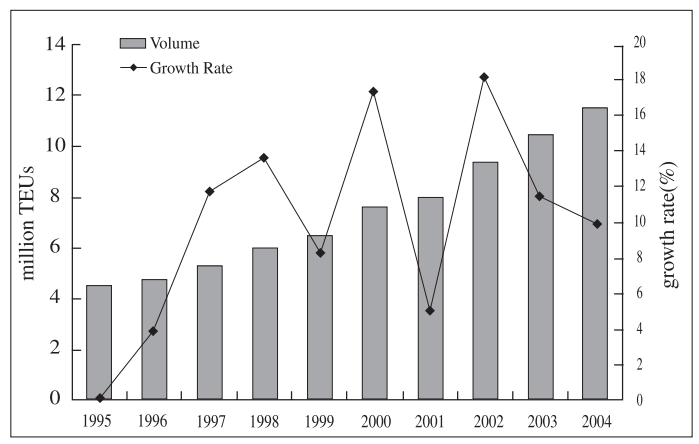


Figure 5. Container volume of the Port of Kaohsiung (1995-2004)

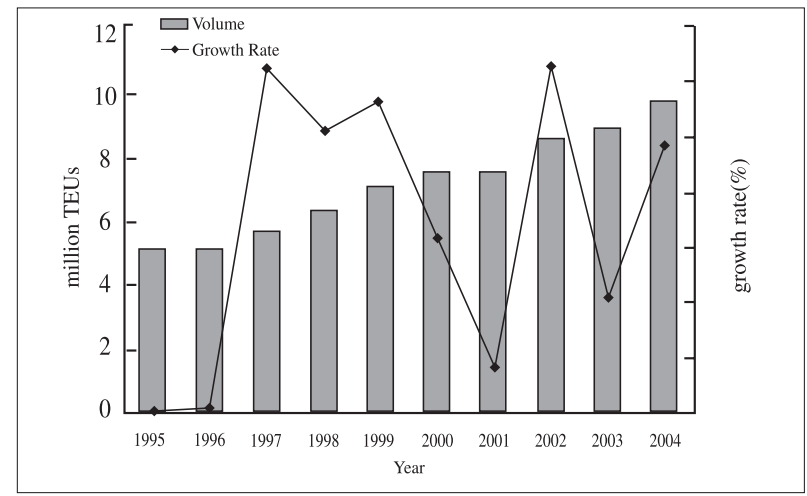

Table 2. Possible container volume and handling capacity of the Port of Shanghai (700,000 TEUs/berth)

\begin{tabular}{c|c|c|c|c|c}
\hline \multirow{2}{*}{ year } & \multicolumn{3}{|c|}{$\begin{array}{c}\text { Possible container volume } \\
\text { (million TEU) }\end{array}$} & $\begin{array}{c}\text { Berth } \\
\text { no. }\end{array}$ & $\begin{array}{c}\text { Handling capacity } \\
\text { (m TEUs) }\end{array}$ \\
\cline { 2 - 4 } & optimistic & Stable & pessimistic & & 27.3 \\
\hline 2006 & 24.50 & 24.00 & 21.00 & 39 & 38.5 \\
\hline 2010 & 73.50 & 65.00 & 43.00 & 55 & 52.5 \\
\hline 2015 & 280.00 & 231.00 & 108.00 & 75 & \\
\hline
\end{tabular}

Table 3. Possible container volume and handling capacity of the Port of Kaohsiung (500,000 TEUs/berth)

\begin{tabular}{c|c|c|c|c|c}
\hline \multirow{2}{*}{ year } & \multicolumn{3}{|c|}{$\begin{array}{c}\text { Possible container volume } \\
\text { (million TEU) }\end{array}$} & \multirow{2}{*}{$\begin{array}{c}\text { Berth } \\
\text { no. }\end{array}$} & $\begin{array}{c}\text { Handling capacity } \\
\text { (m TEUs) }\end{array}$ \\
\cline { 2 - 4 } & optimistic & Stable & pessimistic & & 13.00 \\
\hline 2006 & 12.10 & 11.20 & 10.30 & 26 & 15.00 \\
\hline 2010 & 18.50 & 14.60 & 11.00 & 30 & 17.50 \\
\hline 2015 & 33.50 & 20.50 & 12.30 & 35 & \\
\hline
\end{tabular}

Table 4. Possible container volume and handling capacity of the Port of Busan* and Kwangyang (500,000 TEUs/berth)

\begin{tabular}{c|c|c|c|c|c|c}
\hline \multirow{2}{*}{ year } & \multicolumn{3}{|c|}{$\begin{array}{c}\text { Possible container volume } \\
\text { (million TEUs) }\end{array}$} & \multirow{2}{*}{$\begin{array}{c}\text { Busan } \\
\text { berth no. }\end{array}$} & $\begin{array}{c}\text { Kwangyang } \\
\text { berth no. }\end{array}$ & $\begin{array}{c}\text { Handling } \\
\text { capacity } \\
\text { (m TEUs) }\end{array}$ \\
\cline { 2 - 4 } & optimistic & stable & pessimistic & & 9 & 19.50 \\
\hline 2006 & 14.40 & 13.00 & 11.70 & 30 & 24 & 35.00 \\
\hline 2010 & 33.00 & 23.00 & 16.50 & 46 & 24 & 37.00 \\
\hline 2015 & 107.00 & 52.00 & 28.00 & $50^{*}$ & 24 \\
\hline
\end{tabular}

"based on development announced by the Busan New Port Project 
Figure 6. Comparison of the ports of Shanghai, Busan and Kaohsiung in 2010

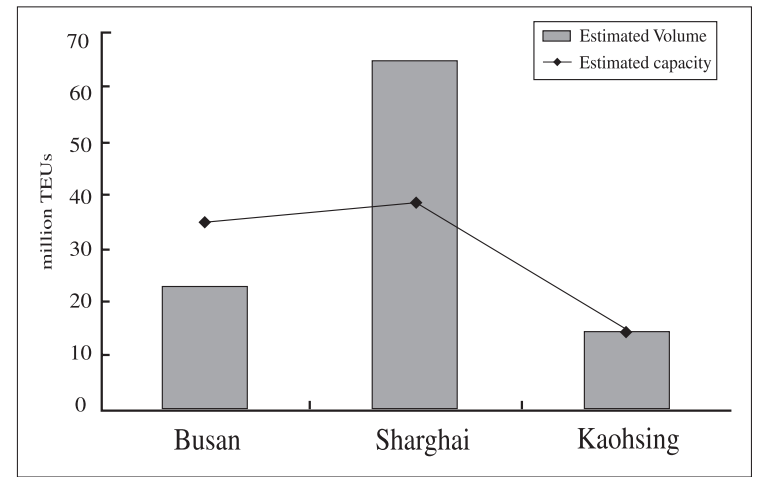

\section{IV . Attractiveness of Ports}

After the supply and demand of container handling capacity has been examined, the second part of the study is to examine the attractiveness of ports. From the perspective of container carriers, the supply of handling capacity is not the only major factor to be considered; the quality of the business environment of the port is another. Many factors influence the "business environment" of the port - in other words, its "attractiveness."

To quantify the "attractiveness" of each port, senior managers from both container shipping lines and port authorities were interviewed to find which factors should be considered. Twelve factors were collected and then divided into four groups (as shown in Table 5). Further, a questionnaire designed based on these factors was designed to quantify the influence of each factor on the "attractiveness" of the port. The analytic hierarchy process (AHP) has been used to quantify the weight of each of the factor(as show in table 6). Finally, these factors are used as the basis to measure the attractiveness of both Busan and Kaohsiung(as show in Table 7).

Table 5. Factors used to measure port "attractiveness"

\begin{tabular}{c|l}
\hline Major Index & \multicolumn{1}{|c}{ Secondary Index } \\
\hline \multirow{4}{*}{ 1. Port Location } & 1. Near import/export area \\
\cline { 2 - 2 } & 2. Near major shipping route \\
\cline { 2 - 2 } & 3. Economic development in the hinterland \\
\hline \multirow{2}{*}{$\begin{array}{c}\text { 2. Port Facilities and } \\
\text { Management }\end{array}$} & 1. Port infrastructure \\
\cline { 2 - 2 } & 2. Container flow efficiency \\
\cline { 2 - 2 } & 3. Port MIS \\
\hline \multirow{2}{*}{$\begin{array}{c}\text { 3. Port Operation and } \\
\text { Management }\end{array}$} & 1. Ship service efficiency \\
\cline { 2 - 2 } & 2. Port security \\
\cline { 2 - 2 } & 3. Port management efficiency \\
\hline \multirow{4}{*}{ 4. Port Charges } & 1. Container handling cost \\
\cline { 2 - 2 } & 2. Container stowage cost \\
\cline { 2 - 2 } & 3. Tariff flexibility \\
\hline
\end{tabular}


Table 6. Weight of each factor

\begin{tabular}{|c|c|c|c|c|c|}
\hline Major Index & Weight & Secondary Index & Weight & Total Score & Ranking \\
\hline \multirow{3}{*}{ 1. Port Location } & \multirow{3}{*}{0.35} & 1. Near import/export area & 0.34 & 0.1190 & 3 \\
\hline & & 2. Near major shipping route & 0.27 & 0.0945 & 4 \\
\hline & & $\begin{array}{l}\text { 3. Economic development in the } \\
\text { hinterland }\end{array}$ & 0.39 & 0.1365 & 1 \\
\hline \multirow{3}{*}{$\begin{array}{l}\text { 2. Port Facilities and } \\
\text { Management }\end{array}$} & \multirow{3}{*}{0.34} & 1. Port infrastructure & 0.35 & 0.1190 & 3 \\
\hline & & 2. Container flow efficiency & 0.25 & 0.0850 & 5 \\
\hline & & 3. Port MIS & 0.40 & 0.1360 & 2 \\
\hline \multirow{3}{*}{$\begin{array}{l}\text { 3. Port Operation and } \\
\text { Management }\end{array}$} & \multirow{3}{*}{0.14} & 1. Ship service efficiency & 0.47 & 0.0658 & 7 \\
\hline & & 2. Port security & 0.15 & 0.0210 & 11 \\
\hline & & 3. Port management efficiency & 0.38 & 0.0532 & 9 \\
\hline \multirow{3}{*}{ 4. Port Charges } & \multirow{3}{*}{0.17} & 1. Container handling cost & 0.46 & 0.0782 & 6 \\
\hline & & 2. Container stowage cost & 0.22 & 0.0374 & 10 \\
\hline & & 3. Tariff flexibility & 0.32 & 0.0544 & 8 \\
\hline
\end{tabular}

In respect to the business environment, there are huge differences between Busan and Kaohsiung. The major differences are illustrated below:

1. Busan has changed from a dedicated terminal to a terminal operator allowing all shipping lines to enjoy high-quality container loading and unloading service. Although Kaohsiung has announced conversion of its port from dedicated terminal to terminal operator, its nature as a dedicated terminal has not changed at all.

2. The Busan port authority has been privatized, which has allowed the port to adopt more flexible and competitive strategies. The liberalization and privatization of the Kaohsiung Harbor Bureau, however, will not happen in the near future despite more than ten years of discussions toward this.

3. Busan has established a well-organized shipping and container information infrastructure, which allows an efficient and cost-effective flow of information and may attract international shipping lines to select Busan as a hub in Asia. Although Kaohsiung has tried to build similar information system, a lack of support from the central government coupled with funding problems have resulted in only basic one planned to be constructed in 2006.

4. Lack of The financal support from central government for port construction pending the development of Kaohsiung port. The policy of Taiwan's central government is to build basic infrastructure only and have the remainder be constructed by terminal operators. It takes years for terminal operators to negotiate with the government for better conditions and cooperation, which slows port development. In turn, this makes it difficult to convince terminal operators to invest billions of dollars to set up transshipment in Kaohsiung. 
The above information was provided to senior managers of shipping lines along with the questionnaire they responded to about the "attractiveness" of Busan and Kaohsiung. The results of the evaluation by senior shipping managers of "port attractiveness" between Busan and Kaohsiung are given below(as shown in Table 7):

Table 7. Comparison of port attractiveness of Busan and Kaohsiung

\begin{tabular}{|c|c|c|}
\hline Factor & Busan & Kaohsiung \\
\hline 1. Near import/export area & 1.70 & 2.38 \\
\hline 2. Near major shipping route & 1.62 & 2.16 \\
\hline 3. Economic development in the hinterland & 2.34 & 2.73 \\
\hline Sub-total & 5.66 & 7.27 \\
\hline 4. Port infrastructure & 3.15 & 2.10 \\
\hline 5. Container flow efficiency & 2.00 & 1.75 \\
\hline 6. Port MIS & 3.60 & 2.00 \\
\hline Sub-total & 8.75 & 5.85 \\
\hline 7. Ship service efficiency & 4.23 & 3.29 \\
\hline 8. Port security & 1.20 & 1.20 \\
\hline 9. Port management efficiency & 3.42 & 2.66 \\
\hline Sub-total & 8.85 & 7.15 \\
\hline 10. Container handling cost & 3.22 & 2.76 \\
\hline 11. Container stowage cost & 1.98 & 1.32 \\
\hline 12. Tariff flexibility & 2.88 & 2.56 \\
\hline Sub-total & 8.08 & 6.64 \\
\hline Total & 7.57 & 6.66 \\
\hline
\end{tabular}




\section{Conclusion}

Based on the research results of both the supply and demand of container-handling capacity and the attractiveness of ports, the strategic matrix between Busan and Kaohsiung could be drawn, as illustrated below:

Figure 7. Strategic matrix between Busan and Kaohsiung in 2010

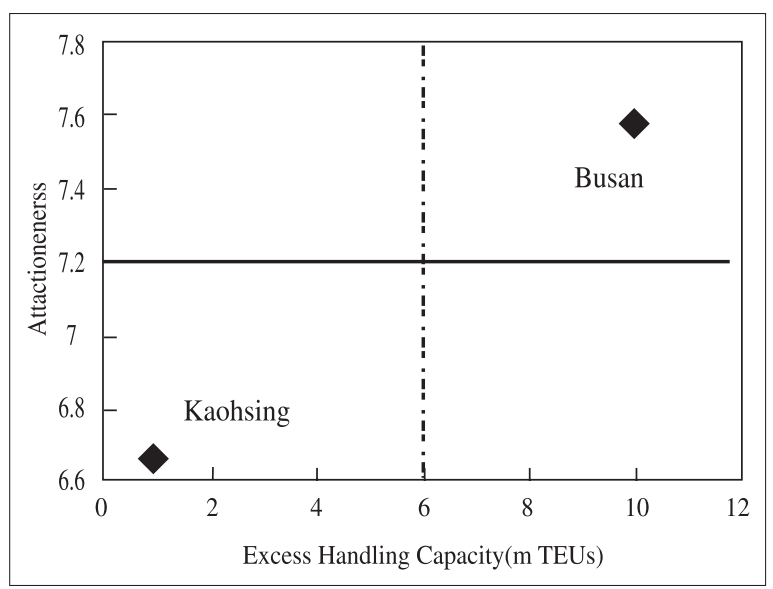

Busan and Kaohsiung are located as opposite poles, reflecting difference in port policy. Busan shows advantages that could make it the mega-hub in Asia, while Kaohsiung is in a poor position to attract transshipment business.

This study analyses the strategies implemented by Busan and Kaohsiung, and the results show the possible development in the future. Owing to limits of time and resources, this study could not cover all of the ports in Asia; an expanded version would be interesting for researchers in inter-port competition.

Another interesting issue is which policies these ports, especially Busan and Kaohsiung, have adopted. How did Kaohsiung, long a shipping center, lose so much of its competitiveness? Meanwhile, Busan has renewed its hardware (new port) and software (business environment) in recent years, which has enabled its vision of becoming a "global hub" a reality. 
Reference

1. G De Monie (1998), Strategies for global and regional ports: the case of Caribbean container and cruise ports.

2. Dong-Wook Song (2003), Port Co-opetition in Concept and Practice, Maritime Policy and Management, Vol.30, No.1.

3. Shigeru Yoshida (2004), Structural Changes of Container Route Network in East Asia, III International Port Forum, Gwang Yang, Republic of Korea.

4. Containerisation International Yearbook, various years.

5. http://www.hutchison-whampoa.com

6. http://my.tdctrade.com

7. http://www.portshanghai.com

8. http://www.pusan.momaf.go.kr

9. http://www.modernterminals.com 